\title{
Management of Fournier's Gangrene; A Randomized Controlled Trial at High Volume Center Comparing the Efficacy of Honey and Eusol Dressing in Wound Healing
}

\author{
Syed Farhan Ahmed, Imran Memon, Zakir Hussain Rajpar, Muhammad Asim, \\ Adnan Anwar, Wajeeha Elahi
}

\begin{abstract}
OBJECTIVE: To assess the effectiveness of honey dressing in Fournier's Gangrene against conventional Edinburgh University solution of lime (EUSOL) dressing.

METHODOLOGY: This was a prospective experimental study conducted in Liaquat National Medical College and Hospital Karachi for duration of 5 and half years. Total 44 patients having gangrene and no co morbid conditions were included in this study. Patients who had co-morbid conditions like deranged coagulation profile and CVA, who were not willing to participate or loss to follow up were excluded from the study. After getting baseline blood workup (i.e. CBC, S. Creatinine, S. Electrolytes, Urine D/R, C/S and Diabetic workup) done and taking consent, the patients were immediately shifted to operation theatre, the incision and drainage was performed, and the necrotic tissues were debrided. Pus cultures were sent, and patients were started on routine intravenous antibiotics $\left(3^{\text {rd }}\right.$ generation Cephalosporin and metronidazole). A Dressing of wound was done randomly by honey in Group A and by Eusol in Group B. Patients were discharged after wound was completely healed. The data were obtained and analyzed by using SPSS version 20. Mann-Whitney U-test and chi-square test was applied to find out the significance.

RESUTS: The patients in Group A got slough cleared in $4.82 \pm 0.96$ days, on average requiring $3.22 \pm 0.75$ number of debridement's, complete wound healing and duration of hospital stay being $9.54 \pm 0.74$ days. The patients in Group B got slough cleared in $8 \pm 0.87$ days, requiring $5.32 \pm 0.72$ number of debridement's, complete wound healing and duration of hospital stay $13.68 \pm 1.09$ days. There was a significant difference in slough clearance, number of debridement's required, time taken for complete wound healing and hospital stay between Group A and Group B (P-value <0.001).

CONCLUSION: This study predicted that honey is very valuable in the management of Fournier's gangrene as it ensured early clearance of slough, required lesser number of debridement's, had early wound healing and had relatively shorter duration of stay in hospital than those treated with conventional EUSOL as dressing material
\end{abstract}

KEYWORDS: Honey, Eusol, Fournier's gangrene

This article may be cited as: Ahmed SF, Memon I, Rajpar ZH, Asim M, Anwar A, Elahi W. Management of Fournier's Gangrene; A Randomized Controlled Trial at High Volume Center Comparing the Efficacy of Honey and Eusol Dressing in Wound Healing. J Liaquat Uni Med Health Sci. 2019;18(01):06-11. doi: 10.22442/jlumhs.191810593

\section{INTRODUCTION}

Fournier's gangrene is defined as infective fasciitis of perineal i.e. penis and scrotum, and perianal regions and is a surgical emergency that requires immediate debridement of dead tissue and antibiotic treatment which may be lethal if not managed properly ${ }^{1}$. Fournier's gangrene most frequently affects during third and sixth decade of life ${ }^{2}$. The mortality rate from Fournier's gangrene is estimated to be $20 \%{ }^{3}$. It is an inflammatory process leading to end arteritis which can be caused by multiple organisms ${ }^{4}$. The subcutaneous vessels become thrombosed resulting in subcutaneous edema. Various inflammatory mediators are released due to infection and can lead to septicemia and may cause scrotal wall necrosis progressing to sloughing of tissue and exposing testicles. The location of infection, rapid spread and risk of death from septicemia are reasons for its surgical emergency. The perineal and perianal region are prone to develop infection as they respond to inflammation leading to subcutaneous edema causing hypoxiaand necrosis of skin $^{5}$. The diagnosis of Fournier's gangrene is based on history and physical examination, although computed tomography (CT) scan and ultrasound are also helpful in establishing diagnosis $^{6-8}$. Immediate surgical removal of and 
debridement of necrotic tissue is desirable, followed by intravenous fluids, antibiotics according to culture and sensitivity reports and dressing of wound to promote healing. There are multiple types of dressing's options available. The most commonly used dressing material since decade is EUSOL which has the property to generate granulation tissue ${ }^{5}$. The dressing of wound was also being done by honey those days ${ }^{9}$.It is topically applied over the wound. The low $\mathrm{pH}$ of honey (mean 3.9) as compared to eusol which has a much higher $\mathrm{pH}(7.5-8.5)$ and its hygroscopic property (moisture absorbing from air) aids in slough removal and leads to formation of granulation tissue, Honey was first used by E. Efemin year 1993 for treatment of Fournier's gangrene. Re-epithelization is stimulated by enzymatic actions of honey ${ }^{10}$. The bee secretes glucose oxidase from the hypopharyngeal glands that converts glucose to gluconic acid and hydrogen peroxide. The hydrogen peroxide has bactericidal effect and decreases the microorganism in wound. There is a slow and steady release of hydrogen peroxide providing persistent antibacterial effect but not being cytotoxic to tissues in the surrounding ${ }^{11,12}$.

In Pakistan, Fournier's gangrene occurs most commonly in hot and humid months of the year, that it affects males 5 times more frequently than females and that in most $(60 \%)$ of the cases the patients belong to lower socioeconomic group ${ }^{13}$. Moreover, though it has been reported earlier that dressing with honey reduced the healing and hospitalization time and additional $\operatorname{costs}^{17}$, the available data on the effectiveness of honey dressing in the treatment of Fournier's gangrene is limited at best. In order to establish an evidence based local data base, this study was therefore conducted to assess the effectiveness of honey dressing in Fournier's gangrene against conventional EUSOL dressing.

\section{METHODOLOGY}

This was a prospective experimental study conducted in Liaquat National Medical College and Hospital Karachi for duration of 5 and half years, from January 2011 - June 2016. Randomization was done to treat patients and obtain data. Total 44 patients were included through convenient sampling technique in this study after taking written and informed consent. Patients who had Fournier's Disease were included in this study. Patients who had co-morbid conditions like deranged coagulation profile and CVA, who were not willing to participate or loss to follow up were excluded from the study. All patients were admitted through emergency department. After getting baseline blood workup (i.e. CBC, S. Creatinine, S. Electrolytes, Urine $\mathrm{D} / \mathrm{R}, \mathrm{C} / \mathrm{S}$ and Diabetic workup) done and taking consent, the patients were immediately shifted to operation theater and under spinal anesthesia, the incision and drainage was performed, and the necrotic tissues were debrided. Pus cultures were sent, and patients were started on routine intravenous antibiotics till culture and sensitivity reports were available. The dressing of wound was done, and patients were shifted to High Dependency Unit for monitoring up to 48 hours. On $2^{\text {nd }}$ post-operation day a relook surgery was done to remove dead and sloughed tissue from the wound. This was carried on every alternate day until healthy granulation tissue appeared, wound was closed primarily in 40 patients where scrotum was mainly involved, 4 patients were referred to plastic surgery for skin coverage where skin loss was extensive. The patients were randomly divided into two groups, in Group A dressing done by Honey and Group B by EUSOL. Patients were discharged home after wound was completely healed. Data was entered and analyzed through SPSS version 20.0. Quantitative data was presented as mean and standard deviation, median and interquartile range. Shapiro Wilk test was applied to check the normality. Mann Whitney $U$ test was applied to assess the difference. Chi-square test was used to find out the association between quantitative variables,. $\mathrm{P}$-value of $\leq 0.05$ was taken as significant.

\section{RESULTS}

Out of a total 44 patients, Group A patients had mean age of $53.86 \pm 7.69$ years while that of Group B was $56 \pm 7.49$ years. The patients in Group A presented to emergency department at mean of $5.77 \pm 0.922$ days after presentation of symptoms while the Group B patients presented at5.77 \pm 0.92 days after presentation. The patients in Group A got slough cleared in $4.82 \pm 0.96$ days, on average requiring $3.22 \pm 0.75$ number of debridement's, complete wound healing and duration of hospital stay being $9.54 \pm 0.74$ days. The patients in Group B got slough cleared in $8 \pm 0.87$ days, requiring $5.32 \pm 0.72$ number of debridement's, complete wound healing and duration of hospital stay $13.68 \pm 1.09$ days. (Table I)

There was a significant difference in slough clearance, number of debridement's required, time taken for complete wound healing and hospital stay between Group A and Group B (P-value <0.001). (Table II) Among Group A and Group B patients, the socio-economic distribution and presence of associated conditions had equal occurrence in two groups. Group A and B had $17(77.3 \%)$ of poor and 5 $(22.7 \%)$ patients belonging to middle socio-economic status. Diabetes was present in 19(86.4\%) patients in both groupsand alcohol consumption was reported by $3(13.6 \%)$ patients with equal frequency in both the 
Syed Farhan Ahmed, Imran Memon, Zakir Hussain Rajpar, Muhammad Asim, Adnan Anwar, Wajeeha Elahi

groups. The cause of Fournier's gangrene was found to be urethral stricture in $3(13.6 \%)$, epididymo-orchitis in $6(27.3 \%)$, perineal abscess in $5(22.7 \%)$, traumatic catherization in $3(13.6 \%)$, fistula in Ano in $3(13.6 \%)$ and unknown in $2(9.1 \%)$ patients in Group A while in Group B 3(13.6\%) patients had urethral stricture, 8 $(36.4 \%)$ had epididymo-orchitis, $5(22.7 \%)$ had perineal abscess, $3(13.6 \%)$ had traumatic catherization, 2(9.1\%) had fistula in Ano and 1(4.5\%) had unknown cause of Fournier's gangrene. In Group A,Fournier's gangrene affected scrotum and perineum in $12(54.5 \%)$, scrotum and penis in $7(31.8 \%)$ and scrotum along with abdomen in $3(13.6 \%)$ of patients while in Group B Fournier's gangrene affected scrotum and perineum in $7(31.8 \%)$, scrotum and penis in $8(36.4 \%)$ and scrotum along with abdomen in 7 $(31.8 \%)$ of patients. On pus culture report, the organism most frequently isolated from Fournier's gangrene patients was E. Coli, Group A had E. Coli growth in 11(50\%), Group B had E. Coli growth in 12 $(54.5 \%)$ patients. Pseudomonas was found in equal number of patients in both groups $5(22.7 \%)$, while Klebsiella was found in $6(27.3 \%)$ and $5(22.7 \%)$ of patient in group $A$ and $B$ respectively. (Table III) There was no significant difference in socio-economic status, frequency of causes leading to Fournier's gangrene, site and extension of disease and organisms isolated on culture of pus among the two groups.
TABLE III: ASSOCIATION OF DIFFERENT VARIABLES IN BOTH GROUPS

\begin{tabular}{|c|c|c|c|c|}
\hline \multirow{2}{*}{\multicolumn{2}{|c|}{ Variable }} & Group A & Group B & \multirow{2}{*}{$\begin{array}{c}\text { P. } \\
\text { Value }\end{array}$} \\
\hline & & $n(\%)$ & $n(\%)$ & \\
\hline \multirow{2}{*}{$\begin{array}{l}\text { Socioeco- } \\
\text { nomic }\end{array}$} & Poor & 17(77.3) & $17(77.3)$ & \multirow{2}{*}{$>0.99$} \\
\hline & Middle & $5(22.7)$ & $5(22.7)$ & \\
\hline \multirow{2}{*}{$\begin{array}{l}\text { Associa- } \\
\text { tion }\end{array}$} & Diabetes & $19(86.4)$ & $19(86.4)$ & \multirow{2}{*}{$>0.99$} \\
\hline & Alcohol Intake & $3(13.6)$ & $3(13.6)$ & \\
\hline \multirow{6}{*}{ Etiology } & Urethral Stricture & $3(13.6)$ & $3(13.6)$ & \multirow{4}{*}{0.918} \\
\hline & Perineal Abscess & $5(22.7)$ & $5(22.7)$ & \\
\hline & Epididymo-orchitis & $6(27.3)$ & $8(36.4)$ & \\
\hline & \begin{tabular}{|l|} 
Traumatic \\
Catherization
\end{tabular} & $3(13.6)$ & $3(13.6)$ & \\
\hline & Unknown & $2(9.1)$ & $1(4.5)$ & \\
\hline & Fistula in Ano & $3(13.6)$ & $2(9.1)$ & \\
\hline \multirow{3}{*}{$\begin{array}{l}\text { Site and } \\
\text { extension } \\
\text { of disease }\end{array}$} & Scrotum+perineum & $12(54.5)$ & $7(31.8)$ & \multirow{3}{*}{0.225} \\
\hline & Scrotum+penis & $7(31.8)$ & $8(36.4)$ & \\
\hline & Scrotum+Abdomen & $3(13.6)$ & $7(31.8)$ & \\
\hline \multirow{3}{*}{$\begin{array}{l}\text { Organism } \\
\text { on Culture }\end{array}$} & Ecoli & $11(50)$ & $12(54.5)$ & \multirow{3}{*}{0.935} \\
\hline & Pseudomonas & $5(22.7)$ & $5(22.7)$ & \\
\hline & Klebsiella & $6(27.3)$ & $5(22.7)$ & \\
\hline
\end{tabular}

TABLE I: GENERAL PARAMETERS INCLUDING THE FATE OF THE WOUND IN THE TWO GROUPS

\begin{tabular}{|c|c|c|c|c|}
\hline \multirow{2}{*}{ Variables } & \multicolumn{2}{|c|}{ Group A $(n=22)$} & \multicolumn{2}{|c|}{ Group B $(n=22)$} \\
\hline & Median (IQR) & Mean士SD & Median (IQR) & Mean \pm SD \\
\hline Age (Years) & $53.5(48-59.25)$ & $53.86 \pm 7.69$ & $54.5(4963.25)$ & $56 \pm 7.49$ \\
\hline Presentation after symptoms (Days) & $5.5(5-6.25)$ & $5.77 \pm 0.92$ & $5.5(5-6.25)$ & $5.77 \pm 0.92$ \\
\hline Clearance of Slough (days) & $5(4-5)$ & $4.82 \pm 0.96$ & $8(7-9)$ & $8 \pm 0.87$ \\
\hline Number of Debridement (days) & $3(3-4)$ & $3.22 \pm 0.75$ & $5(5-6)$ & $5.32 \pm 0.72$ \\
\hline Wound healing (Days) & $9(9-10)$ & $9.54 \pm 0.74$ & $14(13-14)$ & $13.68 \pm 1.09$ \\
\hline Hospitalization (Days) & $9(9-10)$ & $9.54 \pm 0.74$ & $14(13-14)$ & $13.68 \pm 1.09$ \\
\hline
\end{tabular}

TABLE II: DIFFERENCE IN VARIOUS PARAMETERS OF WOUND HEALING

\begin{tabular}{|l|c|c|c|c|c|}
\hline \multirow{2}{*}{\multicolumn{1}{|c|}{ Variables }} & \multicolumn{2}{c|}{ Group A (n=22) } & \multicolumn{2}{c|}{ Group B (n=22) } & P-value \\
\cline { 2 - 6 } & Mean Rank & Sum of Ranks & Mean Rank & Sum of Ranks & 0.40 \\
\hline Age (Years) & 20.89 & 459.5 & 24.11 & 530.50 & 0.40 \\
\hline Presentation after symptoms (Days) & 22.50 & 495.00 & 22.50 & 495.00 & $>0.99$ \\
\hline Clearance of Slough (Days) & 11.73 & 258 & 33.27 & 732 & $<0.001$ \\
\hline Number of Debridement (Days) & 12.11 & 266.50 & 32.89 & 723.50 & $<0.001$ \\
\hline Wound healing (Days) & 11.50 & 253.00 & 33.50 & 737.00 & $<0.001$ \\
\hline Hospitalization (Days) & 11.50 & 253.00 & 33.50 & 737.00 & $<0.001$ \\
\hline
\end{tabular}




\section{DISCUSSION}

Continuous dressing of wound after surgical debridement plays a pivotal role in treatment of Fournier's gangrene. The conventional way of dressing had been by using EUSOL, but honey is also being used for dressing purposes. The antibiotic properties in honey imparted by enzymes found in it play an important role in wound healing. The gluconic acid along with other organic acids like acetic, butanoic, formic, succinic, lactic malic and pyroglutamic lowers the $\mathrm{pH}$ of honey. The composition of honey varies as bees feed on different plants, nevertheless it contains minute quantities of amino acids, minerals and vitamins that boost the antibacterial properties of honey as dressing material ${ }^{14}$.Some studies have revealed it to inhibit more than 60 species of bacteria (anaerobes, gram positive, gram negative species) and certain yeast like Aspergillus ${ }^{15,16}$. Unprocessed honey has been demonstrated to inhibit most of the fungi and bacteria causing wound infection and surgical infection. ${ }^{17}$

In a study, majority of patients belonged to lower socio -economic class (82.5\%). Many patients were found to be chronic alcoholic while quarter patients had Diabetes Mellitus ${ }^{3}$. In another study, nearly half $(47 \%)$ of the patients were diabetics ${ }^{18}$. According to a study, Alcoholism and Diabetes were most common factors influencing the occurrence of Fournier's gangrene in a study $^{19}$. Our study results were similar to these studies. In our study, majority of the patients 17 $(77.3 \%)$ were poor in both Group A and B. Diabetes was present in $19(86.4 \%)$ of patients in both groupsand alcohol was consumed by $3(13.6 \%)$ patients in two groups.

About $30 \%$ patient had anorectal cause while $32.5 \%$ had urogenital cause of Fournier's gangrene. All patients had scrotal involvement followed by scrotal and penis together being involved. On culture report of pus, E.Coli $(42.5 \%)$ were isolated from majority of samples, Klebsiella Pneumoniae (12.5\%) and Pseudomonas $(7.5 \%)$ were found in few patients ${ }^{5}$. Majority $(86.6 \%)$ had etiology leading to gangrene. Majority patients had scrotum affected followed by penis and perianal area ${ }^{3}$. A study demonstrated $\mathrm{E}$. coli and Klebsiella to be most common organisms being isolated from pus culture of Fournier's gangrene patients $^{20}$. Likewise, the most common organism isolated in our study was also $\mathrm{E}$. Coli $(50 \%$ in group A and $54.5 \%$ in group B). Most of the patient had epididymo-orchitis (Group A $27.3 \%$, Group B 36.4\%) followed by perineal abscess (22.7\% in both Groups). In our study most common site involved was Scrotum and perineum (54.5\%) in Group A and scrotum and penis $(36.4 \%)$ in Group B. The organism mostly isolated from Group A (50\%) and Group B (54.5\%) was E. Coli. Pseudomonas was found in equal number of patients $(22.7 \%)$ in both groups. Klebsiella was slightly more predominant in group A (27.3\%) than group $B(22.7 \%)$.

In a study done in India, mean age of Fournier's gangrene patients was $54.08 \pm 15.47$ years with majority being $>60$ years. Most of the patients visited hospital within 7 days of symptoms ${ }^{5}$. In another study, the mean age of Fournier's gangrene patients was noted to be $47 \pm 15.8$ years ${ }^{17}$. In another study, the mean age was found to be 45.2 years $^{3}$. In our study, The Group A patients had mean age of $53.86 \pm 7.69$ years while that of Group B was $56 \pm 7.49$ years which is slightly higher than other studies. The patients in Group A and Group B presented to emergency department at mean $5.77 \pm 0.922$ days after presentation of symptoms, which is less as compared to study conducted in India.

The use of honey as a wound dressing has been shown to give good results on a very wide range of wound types ${ }^{9}$. It has been reported to heal infected post-operative wounds more quickly than antiseptics and gauze ${ }^{21}$, and has been known to be useful in the treatment of ulcers ${ }^{22}$. It has also been reported to be beneficial to the healing process in Fournier's gangrene specifically ${ }^{23}$, and to result in better clinical and cosmetic results ${ }^{24}$. In a study, the days required for clearance of slough by EUSOL was $6.63 \pm 2.36$ days and $5.92 \pm 1.84$ days for honey dressing. The days taken for regeneration of granulation tissue were $9.62 \pm 4.5$ using EUSOL as dressing and $10.5 \pm 3.79$ using honey as dressing. Mean days the patient was hospitalized were $15.44 \pm 6.9$ days in EUSOL dressing patients and $15.41 \pm 8.41$ days in honey dressing patients. There was no significant difference found on comparison of these parameters between two groups ${ }^{5}$. Another study reported the duration of hospital stay to be significantly shorter in honey treated group than that of EUSOL treated group i.e. 28 days vs. 32 days $^{3}$. Another study reported that healthy granulation appeared in 3 weeks in the group with honey dressing while it appeared in 4 weeks in the group with Eusol dressing; mean hospital stay was 28 days in the former whereas 32 days in the later group ${ }^{25}$. In our study, the patients in Group A got slough cleared in $4.82 \pm 0.96$ days, requiring $3.22 \pm 0.75$ number of debridement's, complete wound healing and duration of hospital stay being $9.54 \pm 0.74$ days. The patients in Group B got slough cleared in $8 \pm 0.87$ days, requiring $5.32 \pm 0.72$ number of debridement's, complete wound healing and duration of hospital stay being $13.68 \pm 1.09$ days. There was a significant difference in slough clearance, number of debridement's required, time taken for complete wound healing and hospital stay between Group A 
and Group B $(p<0.001)$. This showed the clear evidence in effectiveness of honey for wound healing. This study sheds light on honey being useful in treatment of Fournier's gangrene. This type of experiment should be done on greater number of patients to assess each parameter more deeply and with clarity to help establish a valid alternative option for treatment of Fournier's gangrene that is less costly and natural with minimum to zero side effects. The drawback of this study is its limited sample size andobserver bias. For this purpose, a double blind randomized control trial needs to be conducted to further unveil the difference in outcome of wound after getting treated by honey.

\section{CONCLUSION}

This study predicted that honey is very valuable in the management of Fournier's gangrene as it ensured early clearance of slough, required lesser number of debridement's, had early wound healing and had relatively shorter duration of stay in hospital than those treated with conventional EUSOL as dressing material.

Conflict of interest: There was no any conflict of interest.

Funding: There was no any funding agency.

\section{REFERENCES}

1. Kuzaka B, Wróblewska MM, Borkowski T, Kawecki D, Kuzaka P, Młynarczyk G, Radziszewski P. Fournier's Gangrene: Clinical Presentation of 13 Cases. Med Sci Monit. 2018; 24:548-55. doi: 10.12659/MSM.905836.

2. Benjelloun el B, Souiki T, Yakla N, Ousadden A, Mazaz K, Louchi A, et al. Fournier's gangrene: our experience with 50 patients and analysis of factors affecting mortality. World J Emerg Surg. 2013; 8:13. doi: 10.1186/1749-7922-8-13.

3. Sabzi Sarvestani A, Zamiri M, Sabouri M. Prognostic Factors for Fournier's Gangrene; A 10-year Experience in Southeastern Iran. Bull Emerg Trauma. 2013; 1(3):116-22.

4. Chennamsetty A, Khourdaji I, Burks F, Killinger KA. Contemporary diagnosis and management of Fournier's gangrene. Ther Adv Urol. 2015; 7 (4):203-15. doi:10.1177/ 1756287215584740.

5. Ugane SP, Kalbagwar SK, Kurane SB. A clinical study of Fournier's gangrene and use of honey dressing in treatment. Int J Res Med Sci. 2018; 6 (3):932-6. doi:10.18203/2320-6012.jmmrs20180618

6. Unalp HR, Kamer E, Derici H, Atahan K, Balci U, Demirdoven $C$, et al. Fournier's gangrene: evaluation of 68 patients and analysis of prognostic variables. J Postgrad Med. 2008; 54(2):102-5.
7. Kube E, Stawicki SP, Bahner DP. Ultrasound in the diagnosis of Fournier's gangrene. Int J Crit IIIn Inj Sci. 2012; 2(2):104-06. doi: 10.4103/22295151.97276.

8. Santora T, Rukstalis DB. Fournier Gangrene. eMedicine website. (Online) (Cited 2011 March 2). Available from URL: http://emedicine.medscape. com/article/438994-overview.

9. Molan PC. The evidence supporting the use of honey as a wound dressing. Int $\mathrm{J}$ Low Extrem Wounds. 2006; 5(1):40-54.

10. Minden-Birkenmaier B, Bowlin G. Honey-based templates in wound healing and tissue engineering. Bioengineering (Basel). 2018; 5(2): 46. doi: 10.3390/bioengineering 5020046 .

11. Yaghoobi R, Kazerouni A, Kazerouni $O$. Evidence for clinical use of honey in wound healing as an anti-bacterial, anti-inflammatory anti-oxidant and anti-viral agent: a review. Jundishapur J Nat Pharm Prod. 2013; 8(3):100-4.

12. Sharp A. Beneficial effects of honey dressings in wound management. Nurs Stand. 2007;24(7): 66-8.

13. Ullah S, Khan M, Asad UJ. Fournier's gangrene: a dreadful disease. The Surgeon. 2009; 7(3):138142. doi: $10.1016 / S 1479-666 X(09) 80036-X$

14. Robson V, Dodd S, Thomas S. Standardized antibacterial honey (Medihoney) with standard therapy in wound care: randomized clinical trial. J Adv Nurs. 2009; 65(3):565-75. doi: 10.1111/ j.1365-2648.2008.04923.x.

15. Olaitan PB, Adeleke OE, Ola IO. Honey: a reservoir for microorganisms and an inhibitory agent for microbes. Afr Health Sci. 2007; 7(3):159 -65 .

16. Molan PC. The Antibacterial Activity of Honey. 1. The nature of the antibacterial activity. Bee World. 1992; 73(1):5-28.

17. Efem SE, Udoh KT, Iwara Cl. The antimicrobial spectrum of honey and its clinical significance. Infection. 1992; 20(4):227-9.

18. Haidari M, Nazer MR, Ahmadinejad M, Almasi V, Khorramabadi MS, Pournia Y. Honey in the treatment of Fournier's gangrene as an adjuvant: a cross sectional study. J Pak Med Assoc. 2014; 64(5):571-3.

19. Oymacı E, Coşkun A, Yakan S, Erkan N, Uçar $A D$, Yıldırım M. Evaluation of factors affecting mortality in Fournier's Gangrene: Retrospective clinical study of sixteen cases. Ulus Cerrahi Derg. 2014; 30(2):85-9. doi: 10.5152/UCD.2014.2512

20. Aji SA, Alhassan SU, Ujudud M. Fournier's Gangrene: Experience with Management of 46 Cases in a Tertiary Institution. Open J Urol. 2012; 2(3):109-12. 
21. Jull $A B$, Rodgers $A$, Walker N. Honey as a topical treatment for wounds. Cochrane Database Syst Rev. 2008; 4: CD005083. doi: 10.1002/14651858. CD005083.pub2.

22. Yapucu Gunes U, Eşer I. Effectiveness of a honey dressing for healing pressure ulcers. J Wound Ostomy Continence Nurs. 2007; 34(2):184-90.

23. Hejase MJ, Simonin JE, Bihrle R, Coogan CL. Genital Fournier's gangrene: experience with 38 patients. Urology. 1996 May;47(5):734-9.

24. Tahmaz L, Erdemir F, Kibar Y, Cosar A, Yalcýn O. Fournier's gangrene: report of thirty-three cases and a review of the literature. Int J Urol. 2006; 13 (7): 960-67.

25. Subrahmanyam M, Ugane SP. Honey dressing beneficial in treatment of Fournier's gangrene. Indian J Surg. 2003; 66(2):75-77.

\section{彞}

AUTHOR AFFILIATION:

Dr. Syed Farhan Ahmed (Corresponding Author) Assistant Professor Urology Liaquat National Hospital Karachi, Sindh-Pakistan.

Email: syedffarhan@gmail.com

\section{Dr. Imran Memon}

Assistant Professor Urology

Liaquat University Of medical and Health Sciences Jamshoro, Sindh-Pakistan.

\section{Dr. Zakir Hussain Rajpar}

Assistant Professor Urology

Liaquat University Of medical and Health Sciences

Jamshoro, Sindh-Pakistan.

\section{Dr. Muhammad Asim}

Assistant Professor Urology

Dow University of Health Sciences

Karachi, Sindh-Pakistan.

\section{Dr. Adnan Anwar}

Assistant Professor

Isra University Hyderabad, Sindh-Pakistan.

\section{Dr. Wajeeha Elahi}

Consultant

NIBD Hospital Karachi, Sindh-Pakistan. 